\title{
Clinicopathological characteristics and prognosis of signet ring cell carcinoma of the stomach
}

\author{
Kyoung-Joo Kwon • Ki-Nam Shim • \\ Eun-Mi Song $\cdot$ Ju-Young Choi $\cdot$ Seong-Eun Kim $\cdot$ \\ Hye-Kyung Jung $\cdot$ Sung-Ae Jung
}

Received: 19 September 2012/ Accepted: 15 January 2013/Published online: 7 February 2013

(C) The International Gastric Cancer Association and The Japanese Gastric Cancer Association 2013

\begin{abstract}
Background Signet ring cell carcinoma (SRC) of the stomach is a histological type based on microscopic characteristics. Although the distinctive clinicopathological features of SRC have been reported, results are inconsistent and survival outcomes are uncertain.

Methods We retrospectively studied 769 patients with gastric carcinoma who underwent gastrectomy in our institute from 1999 to 2009. Among them, 326 patients $(42.4 \%)$ had early gastric cancer (EGC) and 443 patients $(57.6 \%)$ had advanced gastric cancer (AGC). Sex, age, tumor location, macroscopic type, tumor size, microscopic invasion, and survival rate were compared between patients with SRC, differentiated-, and undifferentiated-type gastric carcinomas.

Results Fifty-one patients (15.6\%) had SRC in EGC; there were significant differences in sex, age, location, macroscopic type, and size between SRC and the differentiated histological type. However, there was no difference between SRC and undifferentiated-type gastric carcinoma, except for the macroscopic type. Fifty-seven patients $(12.9 \%)$ had SRC in AGC. Sex, age, location, size, macroscopic type, perineural invasion, $\mathrm{N}$ stage, and hepatic metastasis were significantly different between SRC and the differentiated histological type. Undifferentiated-type gastric carcinoma differed in sex, macroscopic type, and hepatic metastasis. The overall survival rate
\end{abstract}

K.-J. Kwon · K.-N. Shim ( $₫)$ - E.-M. Song · J.-Y. Choi ·

S.-E. Kim · H.-K. Jung $\cdot$ S.-A. Jung

Department of Internal Medicine, Ewha Womans University

School of Medicine, Ewha Womans University Mokdong

Hospital, 911-1 Mok-dong, Yancheon-gu, Seoul 158-710,

South Korea

e-mail: shimkn@ewha.ac.kr differed between SRC and other cell types $(P<0.001)$. Among all the study patients, age [hazard ratio (HR) 1.013, $P=0.041]$ and tumor, node, and metastasis (TNM) stage (HR 2.350, $P<0.001$ ) were important factors for predicting survival. Omitting patients with palliative resection or metastases, TNM stage was still an important factor for survival (HR 2.077, $P<0.001$ ).

Conclusions Patients with SRC showed similar clinicopathological features with undifferentiated histology. The survival of patients with SRC reflected a better prognosis in patients with undifferentiated gastric carcinoma. However, when narrowing the patients to those with EGC only, survival in EGC patients exhibited no difference between histological types. Among AGC patients, SRC patients had a worse prognosis than other cell types.

Keywords Gastric cancer - Signet ring cell carcinoma . Survival · Prognosis

\section{Introduction}

Signet ring cell carcinoma (SRC) is a histological type based on more than $50 \%$ of the tumor containing extracellular mucinous pools, according to the World Health Organization (WHO) classification. In other classifications, it is classified as "diffuse type" by Lauren, "infiltrative type" by Ming, and "undifferentiated type" by the Japanese classification. Although many studies have reported distinct clinicopathological features in patients with SRC of the stomach, there are still uncertainties with regard to characteristics and survival outcomes. Generally, the biological behavior of SRC has been considered to be different from other cell types, but clinical characteristics and prognosis were inconsistently reported. Some studies reported better 5-year 
survival rates in SRC than in other cell types [1, 2]. However, others reported no significant differences [3] or a poorer prognosis [4-6]. In addition, studies that compared SRC with the other cell types in early gastric cancer (EGC) found that SRC had lower lymph node metastasis with better prognosis than other cell types and suggested endoscopic resection for the treatment of signet ring cell-type EGC patients [7]. However, these results are not confirmed, and others suggest that EGC with SRC should be treated by gastrectomy with lymph node dissection rather than endoscopic treatment $[3,5,8]$. We planned this study to retrospectively analyze the clinicopathological features and long-term survival rates of SRC compared with other cell types in stomach cancer patients.

\section{Patients and methods}

We enrolled 769 patients with histologically proven gastric adenocarcinoma, who underwent curative or palliative gastrectomy at Ewha Womans University Hospital, Seoul, Korea, from January 1999 to December 2009, for this retrospective analysis. The patient follow-up period continued until death or the cutoff date of December 31, 2011. The mean follow-up interval was 105.05 months (range, 0-152 months). Sex, age, tumor size, tumor location, macroscopic appearance, hepatic metastasis, microscopic invasions (venous, perineural, or lymphovascular invasion), WHO histological classification, tumor, node, and metastasis (TNM) stage, type of surgery, associated resection, and adjuvant chemotherapy were recorded. All chemotherapies proceeded after the operation, and there were no other treatment modalities except intravenous systemic anticancer treatments. Lymph node metastasis ( $\mathrm{N}$ stage) and depth of tumor invasion (T stage) were classified according to the 7th edition of the American Joint Committee on Cancer/International Union Against Cancer (AJCC/UICC) TNM staging system [9]. Of these 769 patients, 326 patients had EGC and 443 patients had advanced gastric cancer (AGC). We compared the patients with SRC histology with those with other undifferentiated types (including poorly differentiated and mucinous types) and differentiated types (including well-differentiated and moderately differentiated types), respectively. This study was approved by the Institutional Review Board of Ewha Womans University Hospital (ECT 11-29-32).

\section{Statistical analysis}

Patient characteristics were compared between patients with SRC and those with differentiated and undifferentiated histology. Chi-squared analysis and Student's $t$ test were used to compare the discrete and continuous variables, respectively. The Kaplan-Meier method was used to calculate survival rates, and the survival curves were compared using the log-rank test. Multivariate analysis was performed using the Cox proportional hazards regression model for the analysis of prognosis. All statistical analyses were performed using the Statistical Package for Social Science (SPSS) version 16.0 for Windows (SPSS, Chicago, IL, USA). Differences were considered to be statistically significant at $P<0.05$.

\section{Results}

Clinicopathological characteristics

Among the 769 enrolled patients, 489 were men (64\%), and mean age was $60.9 \pm 12.4$ years. Mean tumor size was $4.08 \pm 3.24 \mathrm{~cm}$. There was a significant difference $(P<0.001)$ in histological type between patients with EGC and those with AGC. Among the 326 EGC patients, 51 patients had SRC (15.6\%), 205 had differentiated histology $(62.9 \%)$, and 70 had an undifferentiated histological type $(21.9 \%)$. Among the 443 AGC patients, 57 had SRC (12.9\%), 170 had differentiated histology (38.4\%), and 216 patients had an undifferentiated histological type $(48.8 \%)$.

The clinicopathological characteristics of patients with EGC are summarized in Table 1. Among EGC patients, SRC was more common in younger patients and in women as compared with the differentiated type (mean age, $55.47 \pm 11.45$ vs. $63.17 \pm 10.55$ years, $P<0.001$; female proportion, 49.0 vs. $27.3 \%, P=0.003$ ). However, there were no differences in age and sex between SRC and the undifferentiated type $(P=0.964$ and $P=0.719$, respectively). About $66 \%$ of differentiated tumors were located in the lower third of the stomach. In contrast, $51 \%$ of SRC tumors were located in the middle third of the stomach $(P=0.001)$. Patients with SRC had no macroscopic elevated lesions, which differed significantly from patients with differentiated and undifferentiated types $(P=0.004$ and $P=0.003$, respectively). There was no difference in microscopic invasions between SRC and other histological types, except for perineural invasion, which was significantly more common in SRC than in the differentiated type (7.8 vs. $1.5 \%, P=0.031$ ). There was no difference in the depth of invasion between SRC and the differentiated type $(P=0.642)$, although there was a tendency $(P=0.051)$ for a tumor of undifferentiated histological type to be more invasive than an SRC tumor.

The clinicopathological characteristics of patients with AGC are summarized in Table 2. For AGC patients, SRC was more common in younger patients and in women and the tumor size was larger than for the differentiated type 
Table 1 Characteristics of patients with early gastric cancer (EGC) according to histological classification

\begin{tabular}{|c|c|c|c|c|c|}
\hline EGC (total, $n=326$ ) & $\begin{array}{l}\text { Differentiated }(\%) \\
n=205(62.9)\end{array}$ & $P$ & $\begin{array}{l}\mathrm{SRC}(\%) \\
n=51(15.6)\end{array}$ & $P$ & $\begin{array}{l}\text { Undifferentiated }(\%) \\
n=70(21.9)\end{array}$ \\
\hline Gender & & 0.003 & & 0.719 & \\
\hline Male & 149 (72.7) & & $26(51.0)$ & & $38(54.3)$ \\
\hline Female & $56(27.3)$ & & $25(49.0)$ & & $32(45.7)$ \\
\hline Age (mean $\pm \mathrm{SD}$, years) & $63.2 \pm 10.6$ & $<0.001$ & $55.5 \pm 11.5$ & 0.964 & $55.4 \pm 12.4$ \\
\hline Location of tumor & & 0.001 & & 0.270 & \\
\hline Upper & $13(6.3)$ & & $3(5.9)$ & & $4(5.7)$ \\
\hline Middle & $56(27.3)$ & & $26(51.0)$ & & $27(38.6)$ \\
\hline Lower & $136(66.3)$ & & $21(41.2)$ & & $39(55.7)$ \\
\hline Whole stomach & $0(0)$ & & $1(2.0)$ & & $0(0)$ \\
\hline Size of tumor $(\mathrm{cm})$ & $2.04 \pm 1.39$ & 0.003 & $2.84 \pm 2.51$ & 0.330 & $2.45 \pm 1.84$ \\
\hline Macroscopic type & & 0.004 & & 0.003 & \\
\hline Elevated & $30(14.6)$ & & $0(0)$ & & $10(14.3)$ \\
\hline Flat & $64(31.2)$ & & $25(49.0)$ & & $21(30.0)$ \\
\hline Depressed & $111(54.1)$ & & $26(51.0)$ & & $39(55.7)$ \\
\hline Venous invasion & & 0.115 & & 0.453 & \\
\hline No & $199(97.1)$ & & $47(92.2)$ & & $67(95.7)$ \\
\hline Yes & $6(2.9)$ & & $4(7.8)$ & & $3(4.3)$ \\
\hline Perineural invasion & & 0.031 & & 0.161 & \\
\hline No & $202(98.5)$ & & $47(92.2)$ & & 69 (98.6) \\
\hline Yes & $3(1.5)$ & & $4(7.8)$ & & $1(1.4)$ \\
\hline Lymphovascular invasion & & 0.671 & & 0.228 & \\
\hline No & $185(90.2)$ & & $45(88.2)$ & & $56(80.0)$ \\
\hline Yes & $20(9.8)$ & & $6(11.8)$ & & $14(20.0)$ \\
\hline T stage & & 0.642 & & 0.051 & \\
\hline Tis & $8(3.9)$ & & $2(3.9)$ & & $0(0)$ \\
\hline $\mathrm{T} 1 \mathrm{a}$ & $106(51.7)$ & & $30(58.8)$ & & $33(47.1)$ \\
\hline $\mathrm{T} 1 \mathrm{~b}$ & $91(44.4)$ & & $19(37.3)$ & & $7(52.9)$ \\
\hline LN metastasis & & 0.701 & & 0.251 & \\
\hline No & $181(88.3)$ & & $46(90.2)$ & & $58(82.9)$ \\
\hline Yes & $24(11.7)$ & & $5(9.8)$ & & $12(17.1)$ \\
\hline Surgical goal & & 0.115 & & 0.453 & \\
\hline Curative & $199(97.1)$ & & $47(92.2)$ & & $67(95.7)$ \\
\hline Palliative & $6(2.9)$ & & $4(7.8)$ & & $7(5.8)$ \\
\hline Chemotherapy & & 0.541 & & 0.379 & \\
\hline No & $183(89.3)$ & & $47(92.2)$ & & $61(87.1)$ \\
\hline Yes & $22(10.7)$ & & $4(7.8)$ & & $9(12.9)$ \\
\hline Type of surgery & & 0.599 & & 0.340 & \\
\hline Subtotal gastrectomy & $137(69.9)$ & & $31(66.0)$ & & $49(74.2)$ \\
\hline Total gastrectomy & $59(30.1)$ & & $16(34.0)$ & & $17(25.8)$ \\
\hline
\end{tabular}

(mean age, $58.18 \pm 15.77$ vs. $63.51 \pm 11.61$ years, $P=0.007$; female proportion, 59.6 vs. $27.1 \%$, $P<0.001)$. There was no difference in age between patients with SRC and those with the undifferentiated type $(P=0.261)$. Tumors of differentiated histological type were more frequently located in the lower third of the stomach than SRC tumors (61.2 vs. $45.6 \%, P=0.016)$.
However, there was no difference in tumor location between SRC and the undifferentiated type $(P=0.533)$. In macroscopic appearance, SRC tumors tend to have a flat and depressed appearance; there was only one case of elevated tumor. SRC tumors were more frequently of the N3 stage (52.6 vs. $20.6 \%, P=0.003)$ and had a higher perineural invasion rate $(56.1$ vs. $32.4 \%, P=0.006)$ than 
Table 2 Characteristics of patients with advanced gastric cancer (AGC) according to histological classification

\begin{tabular}{|c|c|c|c|c|c|}
\hline AGC (total, $n=443$ ) & $\begin{array}{l}\text { Differentiated }(\%) \\
n=170(38.4)\end{array}$ & $P$ & $\begin{array}{l}\text { SRC }(\%) \\
n=57(12.9)\end{array}$ & $P$ & $\begin{array}{l}\text { Undifferentiated }(\%) \\
n=216(48.8)\end{array}$ \\
\hline Gender & & $<0.001$ & & 0.009 & \\
\hline Male & $124(72.9)$ & & $23(40.4)$ & & $129(59.7)$ \\
\hline Female & $46(27.1)$ & & $34(59.6)$ & & $87(40.3)$ \\
\hline Age (mean $\pm \mathrm{SD}$, years) & $63.5 \pm 11.6$ & 0.007 & $58.2 \pm 15.8$ & 0.261 & $60.5 \pm 12.9$ \\
\hline Location of tumor & & 0.016 & & 0.533 & \\
\hline Upper & $27(15.9)$ & & $7(12.3)$ & & $33(15.3)$ \\
\hline Middle & $37(21.8)$ & & $20(35.1)$ & & 69 (31.9) \\
\hline Lower & $104(61.2)$ & & $26(45.6)$ & & $107(49.5)$ \\
\hline Whole stomach & $2(1.2)$ & & $4(7.0)$ & & $7(3.2)$ \\
\hline Size of tumor $(\mathrm{cm})$ & $4.62 \pm 2.5$ & $<0.001$ & $6.35 \pm 4.01$ & 0.368 & $5.82 \pm 3.75$ \\
\hline Macroscopic type & & $<0.001$ & & 0.038 & \\
\hline Elevated & $16(9.4)$ & & $1(1.8)$ & & $10(4.6)$ \\
\hline Flat & $7(4.1)$ & & $16(28.1)$ & & $31(14.4)$ \\
\hline Depressed & $187(82.4)$ & & $40(70.2)$ & & $175(81.0)$ \\
\hline Venous invasion & & 0.689 & & 0.169 & \\
\hline No & $103(60.6)$ & & $38(66.7)$ & & $113(52.3)$ \\
\hline Yes & $60(35.3)$ & & 18 (31.6) & & $93(43.1)$ \\
\hline Unknown & $7(4.1)$ & & $1(1.8)$ & & $10(4.6)$ \\
\hline Perineural invasion & & 0.006 & & 0.726 & \\
\hline No & $108(63.5)$ & & $24(42.1)$ & & $91(42.1)$ \\
\hline Yes & $55(32.4)$ & & $32(56.1)$ & & $115(53.2)$ \\
\hline Unknown & $7(4.1)$ & & $1(1.8)$ & & $10(4.6)$ \\
\hline Lymphovascular invasion & & 0.815 & & 0.472 & \\
\hline No & $64(37.6)$ & & $20(35.1)$ & & $61(28.2)$ \\
\hline Yes & $105(61.8)$ & & $37(64.9)$ & & $154(71.3)$ \\
\hline Unknown & $1(0.6)$ & & $0(0)$ & & $1(0.5)$ \\
\hline T stage & & 0.072 & & 0.121 & \\
\hline $\mathrm{T} 2$ & $46(27.1)$ & & $9(15.8)$ & & 25 (11.6) \\
\hline $\mathrm{T} 3$ & $50(29.4)$ & & $13(22.8)$ & & $72(33.3)$ \\
\hline $\mathrm{T} 4 \mathrm{a}$ & $65(38.2)$ & & $33(57.9)$ & & $98(45.4)$ \\
\hline $\mathrm{T} 4 \mathrm{~b}$ & $9(5.3)$ & & $2(3.5)$ & & $21(9.7)$ \\
\hline $\mathrm{N}$ stage $^{\mathrm{a}}$ & & 0.003 & & 0.428 & \\
\hline No & $49(28.8)$ & & $15(26.3)$ & & $42(19.4)$ \\
\hline N1 & $39(22.9)$ & & $7(12.3)$ & & $35(16.2)$ \\
\hline $\mathrm{N} 2$ & $35(20.6)$ & & $5(8.8)$ & & $32(14.8)$ \\
\hline N3 & $47(27.6)$ & & $30(52.6)$ & & $107(49.5)$ \\
\hline LN metastasis & & 0.716 & & 0.256 & \\
\hline Negative & $49(28.8)$ & & $15(26.3)$ & & $42(19.4)$ \\
\hline Positive & $121(71.2)$ & & $42(73.7)$ & & $174(80.6)$ \\
\hline M stage & & 0.252 & & 0.09 & \\
\hline M0 & $145(85.3)$ & & $52(91.2)$ & & 177 (81.9) \\
\hline M1 & $25(14.7)$ & & $5(8.8)$ & & $39(18.1)$ \\
\hline Hepatic metastasis & & 0.014 & & 0.028 & \\
\hline No & $155(91.2)$ & & $57(100)$ & & $200(92.6)$ \\
\hline Yes & $15(8.8)$ & & $0(0)$ & & $16(7.4)$ \\
\hline Surgical goal & & 0.878 & & 0.880 & \\
\hline Curative & $127(74.7)$ & & $42(73.7)$ & & $157(72.7)$ \\
\hline Palliative & $43(25.3)$ & & $15(26.3)$ & & $59(27.3)$ \\
\hline
\end{tabular}


Table 2 continued

\begin{tabular}{|c|c|c|c|c|c|}
\hline AGC (total, $n=443$ ) & $\begin{array}{l}\text { Differentiated } \\
(\%) n=170 \\
(38.4)\end{array}$ & $P$ & $\begin{array}{l}\mathrm{SRC} \\
(\%) n=57 \\
(12.9)\end{array}$ & $P$ & $\begin{array}{l}\text { Undifferentiated } \\
(\%) n=216(48.8)\end{array}$ \\
\hline Chemotherapy & & 0.730 & & 0.538 & \\
\hline No & $82(48.2)$ & & $29(50.9)$ & & $100(46.3)$ \\
\hline Yes & $88(51.8)$ & & $28(49.1)$ & & $116(53.7)$ \\
\hline Type of surgery & & 0.561 & & 0.752 & \\
\hline Subtotal gastrectomy & $67(39.4)$ & & $20(35.1)$ & & $71(32.9)$ \\
\hline Total gastrectomy & 103 (60.6) & & $37(64.9)$ & & $145(67.1)$ \\
\hline
\end{tabular}

${ }^{\text {a }} \mathrm{N}$ stage: $\mathrm{N} 1=1$ or 2 positive lymph nodes, $\mathrm{N} 2=3-6$ positive lymph nodes, $\mathrm{N} 3=7$ or more positive lymph nodes

those with the differentiated histological type. There was no hepatic metastasis in patients with SRC, and this differed significantly from differentiated and undifferentiated histological types $(P=0.014$ and $P=0.028$, respectively; Table 2). In each histological type, approximately half the patients underwent adjuvant chemotherapy, but there was no statistical difference (SRC vs. differentiated, $P=0.730 ;$ SRC vs. undifferentiated, $P=0.538$ ).

\section{Survival outcomes}

The 10-year survival rate of patients with SRC was $55.4 \%$, which was intermediate to the 10-year survival rate of patients with differentiated histological type $(64.5 \%)$ and undifferentiated histological type $(46.2 \%, P<0.001$; Fig. 1). In 326 EGC patients, the 10-year survival rate of patients with SRC was $84.0 \%$; this rate was higher than the differentiated $(76.0 \%)$ and undifferentiated $(65.7 \%)$ histological types, but the difference was not significant
(Fig. 2, $P=0.675$ ). Among the 443 AGC patients, the 10-year survival of SRC was poor $(26.0 \%)$ compared with patients with differentiated $(50.5 \%)$ and undifferentiated (38.4\%) histological types (Fig. 3, $P=0.044$ ). In 211 AGC patients who received adjuvant chemotherapy, we did not investigate response to chemotherapy or disease-free survival when we compared histological types in patients who had systemic anticancer treatment. Although length of survival seemed to differ by several months, there was no significant difference in mean survival length $(P=0.10)$. To account for interrelationships among the variables of survival, univariate and multivariate analyses were performed. Among the total 769 patients, age, size of tumor, macroscopic type, hepatic metastasis, venous invasion, perineural invasion, lymphovascular invasion, TNM stage, and histological classification were predictive factors of survival in univariate analysis (Table 3 ). In multivariate analysis, age and TNM stage remained independent predictive factors of survival (Table 3). In EGC, age and M
Fig. 1 Overall survival of total patients according to histological classification (logrank test, $P<0.001)$. There was significant difference in survival between gastric carcinoma patients with differentiated, undifferentiated, and signet ring carcinoma (SRC) histological types
Total patients

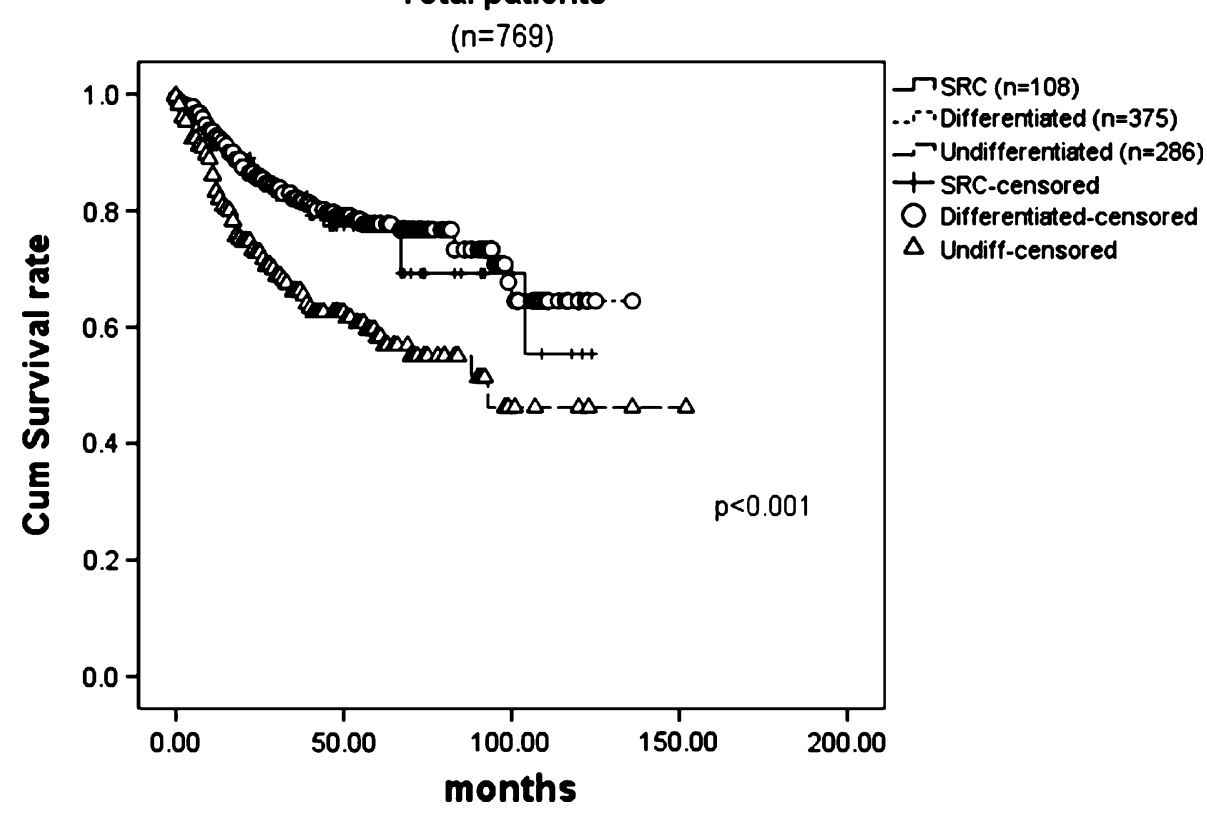


Fig. 2 Survival in patients with early gastric cancer according to histological classification $(P=0.675)$. There was no significant difference in survival between differentiated, undifferentiated, and SRC histological types
Fig. 3 Survival in patients with advanced gastric cancer according to histological classification $(P=0.044)$.

There was significant difference in survival between differentiated, undifferentiated, and SRC histological types
Early gastric cancer
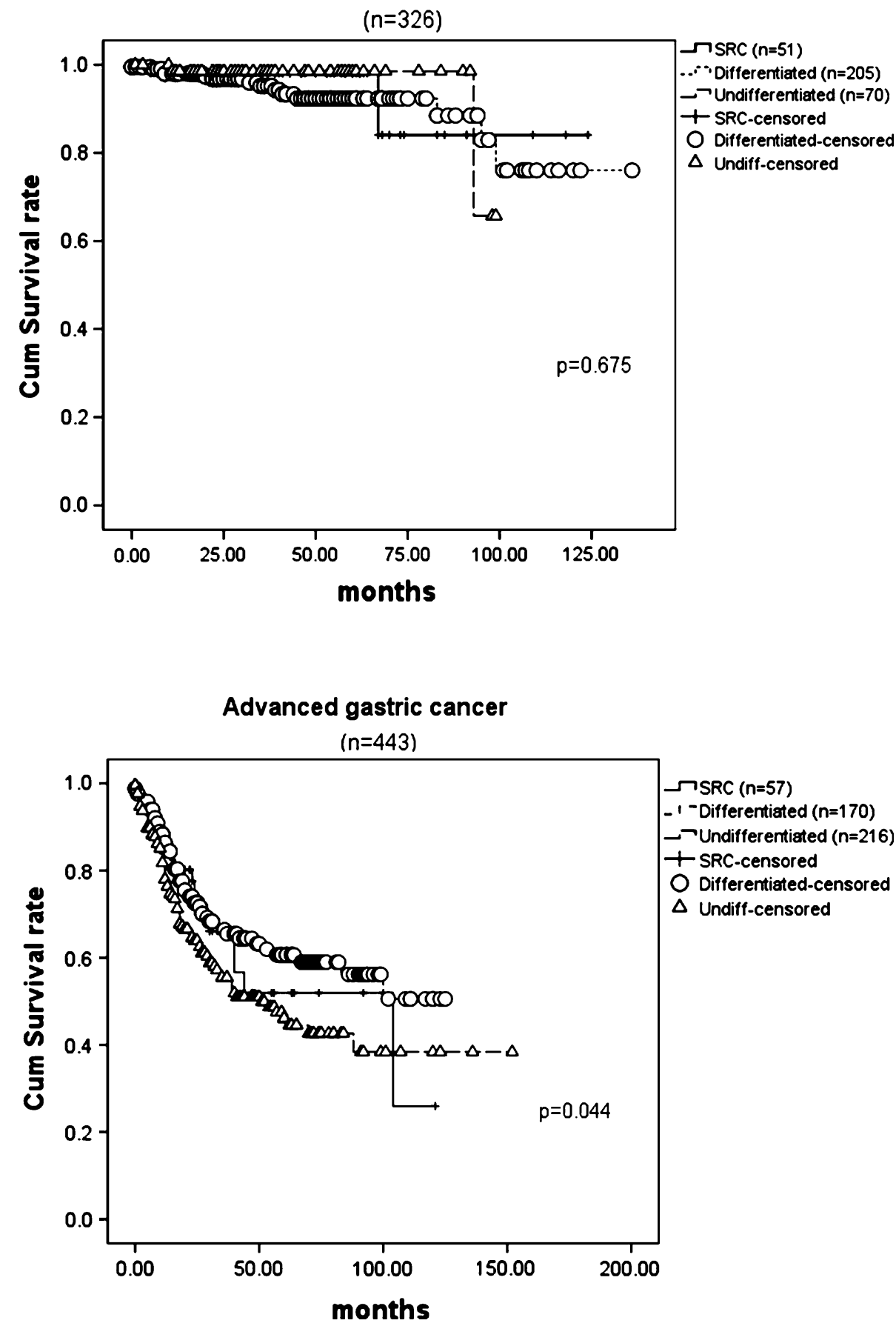

stage were independent predictive factors (Table 4); in AGC, tumor location, TNM stage, curative surgery, and the type of gastric surgery were significant predictive factors affecting survival (see Table 7).

In our analysis, we included patients who had palliative resections or metastatic lesions, and there was a possibility that information from these patients may have influenced statistical calculations of prognostic values. After omitting patients with palliative resections or metastases, 609 patients remained. Among the 609 patients, age, size of the tumor, venous invasion, perineural invasion, lymphovascular invasion, TNM stage, histological classification, chemotherapy, and type of surgery were predictive factors of survival in univariate analysis (Table 5). In multivariate analysis, age, TNM stage, and type of surgery remained independent predictive factors of survival (Table 5). In 309 EGC patients, only age was a meaningful predictive factor by univariate analysis (Table 6); in 300 AGC cases, venous 
Table 3 Prognostic factors in the 769 gastric cancer patients who underwent gastrectomy

LVI lymphovascular invasion

${ }^{a}$ Histological classification: signet ring cell/differentiated/ undifferentiated

Table 4 Prognostic factors in the 326 early gastric carcinoma patients who underwent gastrectomy
LVI lymphovascular invasion

${ }^{a}$ Histological classification: signet ring cell/differentiated/ undifferentiated

\begin{tabular}{|c|c|c|c|c|}
\hline & \multicolumn{2}{|l|}{ Univariate analysis } & \multicolumn{2}{|l|}{ Multivariate analysis } \\
\hline & Hazard ratio $(95 \% \mathrm{CI})$ & $P$ & Hazard ratio $(95 \% \mathrm{CI})$ & $P$ \\
\hline \multicolumn{5}{|l|}{ Gender } \\
\hline Male versus female & $0.901(0.667-1.217)$ & 0.496 & & \\
\hline Age & $1.020(1.007-1.033)$ & 0.002 & $1.013(1.001-1.026)$ & 0.041 \\
\hline Location & $1.159(0.935-1.437)$ & 0.177 & & \\
\hline Size of tumor & $1.171(1.131-1.231)$ & $<0.001$ & $1.036(0.985-1.089)$ & 0.168 \\
\hline Macroscopic type & $1.344(1.045-1.729)$ & 0.021 & $0.968(0.750-1.294)$ & 0.801 \\
\hline Hepatic metastasis & $6.188(3.892-9.840)$ & $<0.001$ & $1.500(0.889-2.532)$ & 0.129 \\
\hline Venous invasion & $3.580(2.651-4.835)$ & $<0.001$ & $1.042(0.718-1.514)$ & 0.828 \\
\hline Perineural invasion & $3.997(2.947-5.422)$ & $<0.001$ & $1.294(0.905-1.848)$ & 0.157 \\
\hline LVI invasion & $4.265(3.113-5.843)$ & $<0.001$ & $1.450(0.954-2.203)$ & 0.082 \\
\hline TNM stage & $2.914(2.492-3.406)$ & $<0.001$ & $2.350(1.904-2.902)$ & $<0.001$ \\
\hline Histological classification $^{\mathrm{a}}$ & $1.611(1.280-2.027)$ & $<0.001$ & $1.138(0.902-1.435)$ & 0.276 \\
\hline Signet ring cell histology & $0.783(0.501-1.222)$ & 0.281 & & \\
\hline
\end{tabular}

\begin{tabular}{|c|c|c|c|c|}
\hline & \multicolumn{2}{|l|}{ Univariate analysis } & \multicolumn{2}{|l|}{ Multivariate analysis } \\
\hline & Hazard ratio $(95 \% \mathrm{CI})$ & $P$ & Hazard ratio $(95 \% \mathrm{CI})$ & $P$ \\
\hline \multicolumn{5}{|l|}{ Gender } \\
\hline Male versus female & $0.736(0.279-1.944)$ & 0.537 & & \\
\hline Age & $1.100(1.047-1.155)$ & $<0.001$ & $1.101(1.045-1.160)$ & $<0.001$ \\
\hline Location & $0.956(0.473-1.929)$ & 0.899 & & \\
\hline Size of tumor & $0.934(0.679-1.290)$ & 0.676 & & \\
\hline Macroscopic type & $0.811(0.436-1.511)$ & 0.509 & & \\
\hline LVI invasion & $1.075(0.248-4.664)$ & 0.923 & & \\
\hline T stage & $0.622(0.274-1.414)$ & 0.257 & & \\
\hline M stage & $8.093(1.805-36.29)$ & 0.006 & $7.432(1.026-53.846)$ & 0.047 \\
\hline TNM stage & $2.130(1.034-4.395)$ & 0.040 & $0.825(0.336-2.029)$ & 0.676 \\
\hline Histological classification $^{\mathrm{a}}$ & $0.869(0.405-1.863)$ & 0.718 & & \\
\hline Signet ring cell histology & $0.869(0.253-2.992)$ & 0.824 & & \\
\hline
\end{tabular}

invasion, lymphovascular invasion, and $\mathrm{N}$ stage were significant factors affecting survival. Of these, $\mathrm{N}$ stage exhibited the highest hazard ratio (HR 2.041; Table 8).

\section{Discussion}

The prevalence of SRC of the stomach has been reported to vary from 3.4 to $39 \%$ [10]. In this study, $14 \%$ of the total patients who underwent gastrectomy had SRC. The proportion of SRC in EGC was $15.6 \%$ compared with $12.9 \%$ in AGC. The higher prevalence of SRC in early EGC is consistent with previous studies [1]. In early SRC, macroscopically depressed lesions predominated over differentiated or undifferentiated histological types $(P=0.004$ and $P=0.003$, respectively). A depressed lesion could easily be detected by endoscopy with an indigo carmine solution spraying method. Moreover, the carcinoma cells are detected early in biopsy specimens because of their typical enriched intracytoplasmic mucin and peripheral compressed nuclei. Consequently, SRC can be detected at an early stage. This unique depressed endoscopic feature of SRC cancer was previously reported in other studies [3, 5, 11]. Among patients with EGC, the SRC type was more frequently observed in younger patients and in female patients than the differentiated type (age, $P<0.001$; female gender, $P=0.003)$, but showed a similar prevalence compared with the undifferentiated type $(P=0.964$ and $P=0.719$, respectively). Earlier reports showed that SRCtype gastric cancer appears to be more frequent in female patients [2]. The reason SRC and undifferentiated-type gastric cancers are predominant in younger and female patients remains unclear. There is a theory that histology may be influenced by sex hormones [12, 13]. In fact, the incidence of gastric cancer shows a male predominance, with a male-to-female ratio of approximately $2: 1$ [14]. This 
Table 5 Prognostic factors in the 609 gastric cancer patients with curative operation and no metastases

LVI lymphovascular invasion, $S T G$ subtotal gastrectomy, $T G$ total gastrectomy

${ }^{a}$ Histological classification: differentiated/signet ring cell/ undifferentiated

Table 6 Prognostic factors in the 309 early gastric carcinoma patients with curative operation and no metastases

LVI lymphovascular invasion

${ }^{\mathrm{a}} \mathrm{N}$ stage: $\mathrm{N} 1=1$ or 2 positive lymph nodes, N2 = 3-6 positive lymph nodes, N3 $=7$ or more positive lymph nodes

b Histological classification: differentiated/signet ring cell/ undifferentiated

\begin{tabular}{|c|c|c|c|c|}
\hline & \multicolumn{2}{|l|}{ Univariate analysis } & \multicolumn{2}{|l|}{ Multivariate analysis } \\
\hline & Hazard ratio $(95 \% \mathrm{CI})$ & $P$ & Hazard ratio $(95 \% \mathrm{CI})$ & $P$ \\
\hline \multicolumn{5}{|l|}{ Gender } \\
\hline Male versus female & $0.907(0.605-1.359)$ & 0.635 & & \\
\hline Age & $1.030(1.012-1.049)$ & 0.001 & $1.030(1.010-1.051)$ & 0.004 \\
\hline Location & $1.217(0.889-1.666)$ & 0.221 & & \\
\hline Size of tumor & $1.162(1.101-1.226)$ & $<0.001$ & $1.002(0.922-1.088)$ & 0.968 \\
\hline Macroscopic type & $1.390(0.988-1.957)$ & 0.059 & & \\
\hline Venous invasion & $2.843(1.848-4.376)$ & $<0.001$ & $1.062(0.620-1.818)$ & 0.827 \\
\hline Perineural invasion & $3.240(2.112-4.972)$ & $<0.001$ & $1.145(0.687-1.910)$ & 0.603 \\
\hline LVI invasion & $3.635(2.422-5.455)$ & $<0.001$ & $1.232(0.703-2.160)$ & 0.465 \\
\hline TNM stage & $2.730(2.181-3.417)$ & $<0.001$ & $2.077(1.495-2.886)$ & $<0.001$ \\
\hline Histological classification $^{\mathrm{a}}$ & $1.382(1.114-1.715)$ & 0.003 & $1.187(0.937-1.503)$ & 0.155 \\
\hline Signet ring cell histology & $0.730(0.399-1.334)$ & 0.306 & & \\
\hline Chemotherapy & $2.347(1.580-3.485)$ & $<0.001$ & $1.316(0.818-2.118)$ & 0.257 \\
\hline Type of surgery (STG vs. TG) & $2.948(1.916-4.535)$ & $<0.001$ & $1.783(1.122-2.833)$ & 0.014 \\
\hline
\end{tabular}

\begin{tabular}{|c|c|c|c|c|}
\hline & \multicolumn{2}{|l|}{ Univariate analysis } & \multicolumn{2}{|l|}{ Multivariate analysis } \\
\hline & Hazard ratio $(95 \% \mathrm{CI})$ & $P$ & Hazard ratio $(95 \% \mathrm{CI})$ & $P$ \\
\hline \multicolumn{5}{|l|}{ Gender } \\
\hline Male versus female & $0.715(0.247-2.067)$ & 0.536 & & \\
\hline Age & $1.088(1.033-1.146)$ & 0.001 & & \\
\hline Location & $0.846(0.406-1.764)$ & 0.655 & & \\
\hline Size of tumor & $0.941(0.663-1.335)$ & 0.731 & & \\
\hline Macroscopic type & $0.921(0.457-1.856)$ & 0.817 & & \\
\hline LVI invasion & $1.314(0.298-5.799)$ & 0.718 & & \\
\hline T stage & $0.790(0.324-1.925)$ & 0.603 & & \\
\hline $\mathrm{N}$ stage $^{\mathrm{a}}$ & $0.928(0.269-3.205)$ & 0.906 & & \\
\hline TNM stage & $1.056(0.119-9.369)$ & 0.961 & & \\
\hline Histologic classification $^{\mathrm{b}}$ & $0.737(0.357-1.519)$ & 0.408 & & \\
\hline Signet ring cell histology & $0.669(0.152-2.950)$ & 0.595 & & \\
\hline Chemotherapy & $1.390(0.383-5.045)$ & 0.616 & & \\
\hline Type of surgery (STG vs. TG) & $1.814(0.670-4.912)$ & 0.241 & & \\
\hline
\end{tabular}

distribution is not clearly explained by the differences in the prevalence of risk factors between the genders. There have been conflicting reports of the effect of sex hormones on the development of gastric cancer $[15,16]$. According to a meta-analysis by Camargo et al. [15], a longer period of fertility and hormonal replacement therapy were each associated with decreased gastric cancer risk. Their analysis supported the hypothesis that longer exposure to the estrogen effects of either ovarian or exogenous origin may decrease the risk of gastric cancer. On the other hand, Matsui et al. [17] reported that, in reviewing the immunohistology of 107 patients with curative resection of gastric cancer, the estrogen receptor-positive rate was slightly higher in younger female patients and in patients with poorly differentiated gastric cancer, and the 10-year cumulative survival rate after surgery was significantly lower in the estrogen receptor-positive cases. The relationship between sex hormones and cancer development needs further investigation. As in previous studies, SRCtype EGC was frequently found in the middle third of the stomach, and it was significantly different from differentiated type $(P=0.001)$. It was reported that SRC cancer originates from the fundic gland where there is no intestinal metaplasia $[2,3,6,18]$.

Previous reports of the prognosis of patients with SRCtype EGC are controversial. Although $\mathrm{Kim}$ et al. [6] reported that the prognosis of SRC-type EGC was similar to that of other histological types, many studies have 
Table 7 Prognostic factors in the 443 advanced gastric carcinoma patients who underwent gastrectomy

LVI lymphovascular invasion

Table 8 Prognostic factors in the 300 advanced gastric carcinoma patients with curative operation and no metastases

LVI lymphovascular invasion

${ }^{\text {a }} \mathrm{N}$ stage: $\mathrm{N} 1=1$ or 2 positive lymph nodes, $\mathrm{N} 2=3-6$ positive lymph nodes, $\mathrm{N} 3=7$ or more positive lymph nodes

b Histological classification: differentiated/signet ring cell/ undifferentiated

\begin{tabular}{|c|c|c|c|c|}
\hline & \multicolumn{2}{|l|}{ Univariate analysis } & \multicolumn{2}{|l|}{ Multivariate analysis } \\
\hline & Hazard ratio $(95 \% \mathrm{CI})$ & $P$ & Hazard ratio $(95 \% \mathrm{CI})$ & $P$ \\
\hline \multicolumn{5}{|l|}{ Gender } \\
\hline Male versus female & $0.851(0.620-1.168)$ & 0.318 & & \\
\hline Location & $1.281(1.034-1.587)$ & 0.024 & $1.284(1.044-1.574)$ & 0.018 \\
\hline Macroscopic type & $0.982(0.760-1.269)$ & 0.889 & & \\
\hline Size of tumor & $1.090(1.044-1.139)$ & $<0.001$ & & \\
\hline Age & $1.012(0.999-1.025)$ & 0.067 & & \\
\hline Hepatic metastasis & $4.143(2.593-6.618)$ & $<0.001$ & & \\
\hline Venous invasion & $2.064(1.505-2.831)$ & 0.001 & & \\
\hline Perineural invasion & $2.013(1.459-2.778)$ & 0.001 & & \\
\hline LVI invasion & $0.455(0.321-0.646)$ & $<0.001$ & & \\
\hline T stage & $1.579(1.311-1.903)$ & $<0.001$ & & \\
\hline $\mathrm{N}$ stage $^{\mathrm{a}}$ & $3.175(1.988-5.072)$ & $<0.001$ & & \\
\hline M stage & $4.492(3.121-6.467)$ & $<0.001$ & & \\
\hline TNM stage & $2.631(2.108-3.285)$ & $<0.001$ & $2.331(1.867-2.911)$ & $<0.001$ \\
\hline Chemotherapy & $1.302(0.949-1.786)$ & 0.102 & & \\
\hline $\begin{array}{l}\text { Surgical goal (palliative vs. } \\
\text { curative) }\end{array}$ & $1.980(1.441-2.721)$ & $<0.001$ & $1.577(1.132-2.198)$ & 0.007 \\
\hline Type of surgery (STG vs. TG) & $1.862(1.290-2.688)$ & 0.001 & $1.608(1.101-2.350)$ & 0.014 \\
\hline Signet ring cell histology & $0.925(0.574-1.492)$ & 0.750 & & \\
\hline
\end{tabular}

reported that the prognosis of SRC-type EGC is significantly better than that of other histological types $[1,2,19$, 20]. In our analysis, even though there was no statistical significance, the 10-year survival rate was $84.0 \%$ for the SRC type, $76.0 \%$ for the differentiated type, and $65.7 \%$ for the undifferentiated type. In SRC-type AGC, deeper tumor invasion, higher LN metastasis rates, and larger tumor sizes than in the differentiated type were observed. Consistent with our data, Jiang et al. [1] reported larger tumor sizes, a higher proportion of Borrmann type IV tumors, and a higher rate of serosal invasion in SRC-type AGC. Previous studies [6, 18] have reported that SRCtype AGC is characterized by the potential to infiltrate the gastric wall, a higher proportion of Borrmann type IV 
tumor, a higher rate of $\mathrm{LN}$ metastasis, deeper tumor invasion, and more peritoneal metastasis. However, it is unique that in our analysis, there was no hepatic metastasis in patients with the SRC types. Patients with SRCtype AGC had a significantly lower survival rate than those with differentiated or undifferentiated types, which is consistent with previous studies [6, 18, 21]. Approximately half the patients in each histological group had adjuvant chemotherapy, but there was no survival difference between groups $(P=0.10$; Table 2$)$. When we compared survival across all stomach cancer patients, we found significant differences among histological types $(P<0.001 ;$ Fig. 1$)$. The differentiated histological type was associated with the highest survival rate, whereas the undifferentiated type had the lowest (10-year survival rate: differentiated, $64.5 \%$; undifferentiated, $38.4 \%$; SRC, $55.4 \%$ ). In 769 total gastric carcinoma patients, the Cox proportional hazards model showed that age and TNM stage at the time of diagnosis were the most important independent predictive factors affecting survival. In EGC, age and $\mathrm{M}$ stage were independent factors (Table 4); in AGC, tumor location, TNM stage, curative surgery, and type of gastric surgery were significant factors affecting survival. To explain predictive factors affecting survival in gastric cancer patients who had curative resection, we excluded patients who had palliative resections or metastases, and 609 patients remained. In 609 patients, age, TNM stage, and the type of surgery were the most important independent predictive factors affecting survival (Table 7). It is unique that in AGC patients, after omitting patients with palliative resections or metastases, venous invasion, lymphovascular invasion, and $\mathrm{N}$ stage were the most important predictive factors affecting survival (Table 8). With results similar to our data, Siewert et al. [22] reported that lymph node ratio and lymph node status are the most important prognostic factors in patients with resected gastric cancer. Nowadays, complete tumor removal with adequate margins of clearance has been widely accepted as a major factor for reduction of locoregional tumor recurrences and improvement of survival time in patients with gastric cancer [23, 24]. Previous studies reported that extended lymph node dissection is the most important factor determining long-term survival in patients with stage II gastric cancer [22]. In EGC patients, however, age was a meaningful predictive factor by univariate analysis.

In conclusion, our analysis showed that SRC has similar clinical features to the undifferentiated histological type. The prognosis of patients with SRC was better than that of the undifferentiated histological type, although survival analysis in EGC patients showed no difference between histological types. Thus, we recommend early detection and invasive treatment regardless of histological type in
EGC. Among AGC patients, SRC patients had a worse prognosis than those with any other histological type of tumor.

\section{References}

1. Jiang CG, Wang ZN, Sun Z, Liu FN, Yu M, Xu HM. Clinicopathologic characteristics and prognosis of signet ring cell carcinoma of the stomach: results from a Chinese mono-institutional study. J Surg Oncol. 2011;103(7):700-3. doi:10.1002/jso.21878.

2. Kunisaki C, Shimada H, Nomura M, Matsuda G, Otsuka Y, Akiyama $\mathrm{H}$. Therapeutic strategy for signet ring cell carcinoma of the stomach. Br J Surg. 2004;91(10):1319-24. doi:10.1002/bjs.4637.

3. Zhang M, Zhu G, Zhang H, Gao H, Xue Y. Clinicopathologic features of gastric carcinoma with signet ring cell histology. J Gastrointest Surg Off J Soc Surg Aliment Tract. 2010;14(4): 601-6. doi:10.1007/s11605-009-1127-9.

4. Piessen G, Messager M, Leteurtre E, Jean-Pierre T, Mariette C. Signet ring cell histology is an independent predictor of poor prognosis in gastric adenocarcinoma regardless of tumoral clinical presentation. Ann Surg. 2009;250(6):878-87. doi:10.1097/ SLA.0b013e3181b21c7b.

5. Li C, Kim S, Lai JF, Hyung WJ, Choi WH, Choi SH, et al. Advanced gastric carcinoma with signet ring cell histology. Oncology. 2007;72(1-2):64-8. doi:10.1159/000111096.

6. Kim JP, Kim SC, Yang HK. Prognostic significance of signet ring cell carcinoma of the stomach. Surg Oncol. 1994;3(4):221-7.

7. Ha TK, An JY, Youn HK, Noh JH, Sohn TS, Kim S. Indication for endoscopic mucosal resection in early signet ring cell gastric cancer. Ann Surg Oncol. 2008;15(2):508-13. doi:10.1245/ s10434-007-9660-9.

8. Lee JH, Choi IJ, Kook MC, Nam BH, Kim YW, Ryu KW. Risk factors for lymph node metastasis in patients with early gastric cancer and signet ring cell histology. Br J Surg. 2010;97(5): 732-6. doi:10.1002/bjs.6941.

9. Washington K. 7th edition of the AJCC cancer staging manual: stomach. Ann Surg Oncol. 2010;17(12):3077-9. doi:10.1245/ s10434-010-1362-z.

10. Theuer CP, Nastanski F, Brewster WR, Butler JA, Anton-Culver H. Signet ring cell histology is associated with unique clinical features but does not affect gastric cancer survival. Am Surgeon. 1999;65(10):915-21.

11. Kim HM, Pak KH, Chung MJ, Cho JH, Hyung WJ, Noh SH, et al. Early gastric cancer of signet ring cell carcinoma is more amenable to endoscopic treatment than is early gastric cancer of poorly differentiated tubular adenocarcinoma in select tumor conditions. Surg Endosc. 2011;25(9):3087-93. doi:10.1007/ s00464-011-1674-5.

12. Matsuyama S, Ohkura Y, Eguchi H, Kobayashi Y, Akagi K, Uchida $\mathrm{K}$, et al. Estrogen receptor beta is expressed in human stomach adenocarcinoma. J Cancer Res Clin Oncol. 2002;128(6): 319-24. doi:10.1007/s00432-002-0336-3.

13. Kitaoka H. Sex hormone dependency and endocrine therapy in diffuse carcinoma of the stomach. Gan To Kagaku Ryoho (Cancer Chemother). 1983;10(12):2453-60.

14. Sipponen P, Correa P. Delayed rise in incidence of gastric cancer in females results in unique sex ratio $(\mathrm{M} / \mathrm{F})$ pattern: etiologic hypothesis. Gastric Cancer. 2002;5(4):213-9. doi:10.1007/ s101200200037.

15. Camargo MC, Goto Y, Zabaleta J, Morgan DR, Correa P, Rabkin CS. Sex hormones, hormonal interventions, and gastric cancer risk: a meta-analysis. Cancer Epidemiol Biomark Prev. 2012; 21(1):20-38. doi:10.1158/1055-9965.EPI-11-0834. 
16. Ryu WS, Kim JH, Jang YJ, Park SS, Um JW, Park SH, et al. Expression of estrogen receptors in gastric cancer and their clinical significance. J Surg Oncol. 2012;. doi:10.1002/jso.23097.

17. Matsui M, Kojima O, Kawakami S, Uehara Y, Takahashi T. The prognosis of patients with gastric cancer possessing sex hormone receptors. Surg Today. 1992;22(5):421-5.

18. Otsuji E, Yamaguchi T, Sawai K, Takahashi T. Characterization of signet ring cell carcinoma of the stomach. J Surg Oncol. 1998;67(4):216-20.

19. Chiu CT, Kuo CJ, Yeh TS, Hsu JT, Liu KH, Yeh CN, et al. Early signet ring cell gastric cancer. Dig Dis Sci. 2011;56(6):1749-56. doi:10.1007/s10620-010-1487-8.

20. Hyung WJ, Noh SH, Lee JH, Huh JJ, Lah KH, Choi SH, et al. Early gastric carcinoma with signet ring cell histology. Cancer (Phila). 2002;94(1):78-83.
21. Baik SH, Huang WJ, Lee JH, Lee KY, Noh SH, Min JS. The clinicopathologic characteristics and prognosis of gastric signet ring cell carcinoma. J Korean Surg Soc. 2000;59(6):771-7

22. Siewert JR, Bottcher K, Stein HJ, Roder JD. Relevant prognostic factors in gastric cancer: ten-year results of the German Gastric Cancer Study. Ann Surg. 1998;228(4):449-61.

23. Allgayer H, Heiss MM, Schildberg FW. Prognostic factors in gastric cancer. Br J Surg. 1997;84(12):1651-64.

24. Deng J, Liang H, Sun D, Pan Y. The prognostic analysis of lymph node-positive gastric cancer patients following curative resection. J Surg Res. 2010;161(1):47-53. doi:10.1016/j.jss.2008.12.019. 